\title{
FACTORS INFLUENCING SELF-PERCEPTION OF HEALTH STATUS
}

\author{
Dorota Kaleta ${ }^{1}$, Kinga Polańska², Elżbieta Dziankowska-Zaborszczyk ${ }^{1}$, Wojciech Hanke ${ }^{2,3}$, Wojciech Drygas $^{1}$ \\ ${ }^{1}$ Department of Preventive Medicine, Medical University, Łódź, Poland \\ ${ }^{2}$ Department of Environmental Epidemiology, Institute of Occupational Medicine, Łódź, Poland \\ ${ }^{3}$ Department of Informatics and Medical Statistics, Medical University, Łódź, Poland
}

\begin{abstract}
SUMMARY
The aim of this study was to evaluate subjective health status of $Ł o ́ d z ́$ adult population and to determine the factors affecting their self-perception of health. The study population consisted of randomly selected 1,056 adults aged 20-74 years from Łódź district. Logistic regression model was applied to assess the factors influencing the self-perception of health. More than $30 \%$ of study subjects described their health as poor or very poor. There were no statistically significant differences between men and women regarding self-perception of health $(p>0.05)$. Older people more frequently reported their health as poor and very poor compared to those younger than 25 years of age. Four percent of men and $10 \%$ of women younger than 25 years of age described their health as poor or very poor whereas in age category $45-54$ years that percentage increased to more than 40\% (men RR=16.3; $p<0.001$, women RR=7.5; $p<0.001$ ), in 55-64 to 60\% (men RR=18.6; $p<0.001$, women $R R=10.0 ; p<0.001$ ) and for people older than 64 years of age to $60 \%$ for men ( $R R=12.6 ; p<0.01$ ) and $72 \%$ for women ( $R R=13.4 ; p<0.001)$. People with lower educational degree perceived their health as worse compared to those with university diploma (men RR=5.3; $p<0.001$; women 4.6; $p<0.001$ ). The risk of indicating the health as poor or very poor was 3.4 times higher for unemployed men comparing to employed ( $p<0.001)$ and 1.5 for unemployed women compared to employed ( $p>0.05$ ). Men indicating no leisure-time physical activity significantly more frequently described their health as poor or very poor than men with satisfactory level of recreational physical activity $(R R=2.2 ; p<0.01)$. Current and former smoker men described their health as worse compared to non-smokers (current smokers RR=1.5; $p>0.05$; former smokers RR=1.8; $p>0.05$ ). Preventive programs aimed at improving self-perceived health should concentrate on increasing recreational physical activity and elimination of smoking. Those actions should in particular target people in older age category.
\end{abstract}

Key words: subjective health, smoking, leisure-time physical activity, educational level, age

Address for correspondence: D. Kaleta, Department of Preventive Medicine, Medical University, Żeligowskiego 7/9, 90-643 Łódź, Poland. E-mail: dkaleta@op.pl

\section{INTRODUCTION}

Epidemiological data indicate that significant determinants of human health can be categorized in four major groups: lifestyle (50\%), environment (20\%), human biology (20\%) and healthcare services (10\%) (1). Of the preventable risks factors responsible for morbidity and mortality, the WHO publication "Comparative Quantification of Health Risks" lists the top ten as: childhood and maternal underweight; unsafe sex; high blood pressure; tobacco; alcohol; unsafe water, sanitation and hygiene; high cholesterol; indoor smoke from solid fuels; iron deficiency and overweight/ obesity (2). Among non-modifiable factors influencing the health status the most important are gender and age. Women are characterized by higher levels of morbidity than men, but mortality rates are higher and life expectancy is considerably lower for man. The risk of most diseases increases significantly with age. Socioeconomic factors like educational level, employment and income which significantly influence the health status should be taken into account as well.

WHO definition of health and diseases endorsees the usefulness and necessity of performing subjective health assessment which takes into consideration not only the state of somatic but also mental health (3). Furthermore, self-perception of one’s own health reflects the capability to function in a definite social and organizational situation and is regarded as a prognostic indicator of prevalence of various chronic diseases, affecting their prognosis $(4,5)$. Individuals with low values of self-perceived health status may more frequently use medical services and have higher absence from work as compared to those with opposite attitude towards their health (6). This method is not expensive, relatively not very complicated and therefore often incorporated into investigations on large populations. Advantages that are indicated above cause that global self-assessments of health have been used extensively as indicator of health status and effectiveness of preventive programmes in both adolescent and adult population-based studies (7-10).

Epidemiological data indicate that higher level of education, higher income, non-smoking status, recreational physical activity, being male, psychological well-being and high self-esteem were found to be associated with higher self-rating of health (11-12). Presence of the risk factors for chronic diseases decreases subjective health assessment but the interactions between lifestyle factors and the subjective health and life quality are not consistent (13). 
The aim of this study was to evaluate subjective health status and to determine the factors affecting self-perception of health among adult population from Łódź district, Poland. Among variety of factors influencing self-perception of health the following were chosen for the analysis: gender, age, educational level, employment status, income, place of residence, leisure-time physical activity and smoking status. The socio-environmental and behavioral factors can interact to help people to feel healthy or to put them at risk and to feel unhealthy.

This paper is concentrating on the population of Łódź district in the frame of the National Health Survey in Poland (Project WOBASZ) conducted in the years 2002-2005 which covered the whole territory of Poland. The Łódź district has the one of the lowest life in 2006 expectancy compared to the other districts in Poland (14). In 2006 the life expectancy at birth in Łódź district was 68.5 years whereas for Poland it was 70.9 years and for person at age 30 it was 40 years and 42.3 respectively (15). Taking this into account it was interesting to look how the people from Łódź district perceive their health status.

\section{MATERIALS AND METHODS}

\section{Study Population}

The methodology of sampling the population from Łódź district was consistent with methodology for the WOBASZ Project which has already been published elsewhere (16).

In Łódź district, 6 areas were randomly selected: 2 small ( $<8,000$ inhabitants), 2 medium (8,000-40,000 inhabitants) and 2 big ( $>40,000$ inhabitants). As a second step samples of 100 women and 100 men aged 20-74 years were randomly selected in each area. Additionally 200 people were selected from Łódź city.

The study sample (1,400 people) was randomly selected from the population of 1.822,149 people in specified age groups from Łódź district which represented about 8\% of that population. About 99\% of the sampled people were contacted of which about $80 \%$ responded to personal invitation to participate in the study. Finally the study population from Łódź district included in the analysis (for which data were completed) consisted of 1056 adults (500 men and 556 women).

All potential study participants were informed about the aims and procedures of the study and were asked to sign an informed consent form. Data collected through the study were confidential. All staff involved in the collection, processing, and analysis of study data were aware of the important responsibility to safeguard the rights of study participants. Respondents were assured that all identifying data, such as their name and address, were not available to anyone outside the project team and were not associated with their responses. All answers were used only for research purposes and were not combined with those of other participant. All confidential project materials were safely secured.

\section{Study Variables}

The investigation procedures were carried out by trained interviewers and nurses in selected out-patient clinics. During the interview, the data on educational level and income (for one person in household after deductions of taxes and social security premiums) were collected. Self-perception of one's own health was classified as very good, good, poor, and very poor based on answer to the question "How do you rate your general state of health?”. The smoking status of the study subjects was established and based on questionnaire data not further confirmed by biochemical measurement. In the analysis we used three category of smoking status: current smoker - person who smokes regularly at least 1 cigarette per day, former smoker - person who used to smoke, but abandoned the habit and does not smoke at present and non-smoker - a person who has never smoked. Active smokers were asked about the number of cigarettes per day, and the age when beginning of smoking habit. To evaluate leisure-time physical activity, based on questionnaire data (frequency of leisure-time physical activity of the duration at least 30 minutes, type and time of the way to the office) three categories were considered: lack of leisure-time physical activity - no conscious recreational physical activity (0 kcal/week), unsatisfactory (0-1,000 kcal/week in men and 0-750 kcal/week in women), and satisfactory (>1,000 $\mathrm{kcal} /$ week in men and $>750 \mathrm{kcal} /$ week in women).

\section{Statistical Analysis}

For the statistical analysis of the longitudinal variables their range (minimum-maximum), mean values (arithmetic mean and median) and also standard deviation were calculated. To compare the frequency of the given categories of quantitative characteristics in the analyzed groups the $\chi^{2}$ test or the $\chi^{2}$ test with Yates correction were implemented. The distribution of measurable characteristics was analyzed using the Shapiro-Wilk test. To compare the mean values between two groups in relation to the type of distribution, the test for two independent trials or the Mann-Whitney test was applied. A significance level was established at $\mathrm{p}=0.05$ for the values included in the critical region of a given distribution. For identification of risk of poor health self-assessment, the logistic regression analysis was performed. In the first stage crude coefficients - relative risk for low self-perceived health status in men and women were calculated. Subsequently, the multifactorial analysis considering simultaneous effect of all variables on the risk of low self-perceived health status in the subjects was employed. All $p$ values were two-sided and $p<0.05$ was set as statistically significant. The statistical analysis was made with the use of the STATGRAPHICS plus 5.1 program.

\section{RESULTS}

\section{Characteristics of the Study Population}

The characteristics of the study population are presented in Table 1 . No statistically significant differences were noticed between men and women regarding the age. The mean age of the study subjects was 45 years. Twenty seven percent of the women and $23 \%$ of men reported primary/secondary education $(\mathrm{p}=0.2)$ and $19 \%$ of women and $15 \%$ of men had university degree $(\mathrm{p}=0.08)$. Employed status was more frequently noted among men (58\%) compared to women (50\%), $(\mathrm{p}=0.008)$. About $42 \%$ of the study subjects lived in big city whereas more than $26 \%$ in small one ( $p>0.05$ ). More than $30 \%$ of study subjects described their health as poor or very poor. More than $40 \%$ of men and $19 \%$ of women were smokers $(p<0.001)$. Non-smoking category was noted in $63 \%$ of women and $32 \%$ of men $(\mathrm{p}<0.001)$. Men smoked longer 
Table 1. Characteristics of the study population

\begin{tabular}{|c|c|c|c|}
\hline Variables & $\begin{array}{c}\text { Women } \\
\mathrm{N}=556(52.6 \%)\end{array}$ & $\begin{array}{c}\text { Men } \\
\mathrm{N}=500(47.4 \%)\end{array}$ & $p$ \\
\hline $\begin{array}{l}\text { Age } \\
\begin{aligned}<25 \\
25-34 \\
35-44 \\
45-54 \\
\\
55-64 \\
65+\end{aligned}\end{array}$ & $\begin{array}{c}62(11.1 \%) \\
112(20.1 \%) \\
92(16.6 \%) \\
124(22.3 \%) \\
84(15.1 \%) \\
82(14.8 \%)\end{array}$ & $\begin{array}{c}47(9.4 \%) \\
90(18.0 \%) \\
94(18.8 \%) \\
125(25.0 \%) \\
80(16.0 \%) \\
64(12.8 \%)\end{array}$ & $\begin{array}{l}0.4 \\
0.4 \\
0.4 \\
0.3 \\
0.8 \\
0.4\end{array}$ \\
\hline $\begin{array}{l}\text { Educational level } \\
\text { Primary/Secondary } \\
\text { High School } \\
\text { University }\end{array}$ & $\begin{array}{l}150(27.0 \%) \\
300(54.0 \%) \\
106(19.1 \%)\end{array}$ & $\begin{array}{l}116(23.2 \%) \\
310(62.0 \%) \\
74(14.8 \%)\end{array}$ & $\begin{array}{l}0.2 \\
0.01 \\
0.08\end{array}$ \\
\hline $\begin{array}{l}\text { Employment status } \\
\text { Not employed } \\
\text { Employed } \\
\end{array}$ & $\begin{array}{l}281(50.5 \%) \\
275(49.5 \%)\end{array}$ & $\begin{array}{l}211(42.2 \%) \\
289(57.8 \%)\end{array}$ & 0.008 \\
\hline $\begin{array}{l}\text { Place of residence } \\
\text { Small } \\
\text { Medium } \\
\text { Big }\end{array}$ & $\begin{array}{l}161(29.0 \%) \\
162(29.1 \%) \\
233(41.9 \%)\end{array}$ & $\begin{array}{l}134(26.8 \%) \\
152(30.4 \%) \\
214(42.8 \%)\end{array}$ & $\begin{array}{l}0.5 \\
0.7 \\
0.8\end{array}$ \\
\hline $\begin{array}{l}\text { Subjective health } \\
\text { Very good } \\
\text { Good } \\
\text { Poor } \\
\text { Very poor }\end{array}$ & $\begin{array}{c}35(6.3 \%) \\
321(57.7 \%) \\
153(27.5 \%) \\
47(8.5 \%)\end{array}$ & $\begin{array}{c}33(6.6 \%) \\
296(59.2 \%) \\
142(28.4 \%) \\
29(5.8 \%)\end{array}$ & $\begin{array}{l}0.9 \\
0.7 \\
0.8 \\
0.1\end{array}$ \\
\hline $\begin{array}{l}\text { Smoking status } \\
\text { Current smoker } \\
\text { Former smoker } \\
\text { Non-smoker }\end{array}$ & $\begin{array}{c}106(19.1 \%) \\
98(17.6 \%) \\
352(63.3 \%)\end{array}$ & $\begin{array}{l}202(40.4 \%) \\
139(27.8 \%) \\
159(31.8 \%) \\
\end{array}$ & $\begin{array}{l}<0.001 \\
<0.001 \\
<0.001\end{array}$ \\
\hline $\begin{array}{l}\text { Number of cigarettes per day } \\
\quad \leq 10 \\
11-20 \\
21+\end{array}$ & $\begin{array}{c}53(50.0 \%) \\
48(45.3 \%) \\
5(4.7 \%) \\
\end{array}$ & $\begin{array}{c}51(25.3 \%) \\
126(62.4 \%) \\
25(12.4 \%) \\
\end{array}$ & $\begin{array}{c}0.001 \\
0.006 \\
0.05 \\
\end{array}$ \\
\hline $\begin{array}{l}\text { Years of smoking } \\
\quad \leq 10 \\
11-20 \\
21-30 \\
31-40 \\
41+\end{array}$ & $\begin{array}{c}22(20.8 \%) \\
22(20.8 \%) \\
39(36.8 \%) \\
19(17.9 \%) \\
4(3.8 \%)\end{array}$ & $\begin{array}{l}34(18.8 \%) \\
38(18.8 \%) \\
62(30.7 \%) \\
42(20.8 \%) \\
26(12.9 \%)\end{array}$ & $\begin{array}{c}0.5 \\
0.8 \\
0.3 \\
0.7 \\
0.02\end{array}$ \\
\hline $\begin{array}{l}\text { Income (PLN per month per capita) } \\
\quad<1,000 \\
\quad \geq 1,000\end{array}$ & $\begin{array}{c}516(92.8 \%) \\
40(7.2 \%) \\
\end{array}$ & $\begin{array}{c}431(86.2 \%) \\
69(13.8 \%) \\
\end{array}$ & $<0.001$ \\
\hline $\begin{array}{l}\text { Leisure-time physical activity } \\
\text { Satisfactory level } \\
\text { Insufficient level } \\
\text { Lack }\end{array}$ & $\begin{array}{l}167(30.0 \%) \\
275(49.5 \%) \\
114(20.5 \%)\end{array}$ & $\begin{array}{l}168(33.6 \%) \\
213(42.6 \%) \\
119(23.8 \%)\end{array}$ & $\begin{array}{c}0.2 \\
0.03 \\
0.2\end{array}$ \\
\hline
\end{tabular}

and more cigarettes per day compared to women. About $13 \%$ of men and $4 \%$ of women smoked more then 40 years $(p=0.02)$. More than 20 cigarettes per day was smoked by $12 \%$ of men and $5 \%$ of women $(p=0.05)$. The percentage of men indicating that income per month per one household was 1,000 PLN or more was $14 \%$ whereas among women it was $7 \%(\mathrm{p}<0.001)$. The satisfactory level of physical activity was noted among $30 \%$ of women and $34 \%$ of men $(\mathrm{p}=0.2)$ whereas the lack of leisure-time physical activity was stated by more than $20 \%$ of study subjects $(p=0.2$ ).

\section{Risk Factors for Poor and Very Poor Subjective Health}

There were no statistically significant differences between men and women regarding self-perception of health $(\mathrm{p}>0.05)$ (Table 1). Only $6 \%$ of the people described their health as very good $(p=0.9)$. Thirty six percent of women and $34 \%$ of men described their health as poor or very poor ( $>0.05)$. Self-perception of health depending on different socio-demographic characteristics for men and women is presented in Tables 2 and 3. Older peo- 
Table 2. Relative risk (RR) and 95\% confidence interval $(95 \% \mathrm{Cl})$ for poor and very poor subjective heath depending on sociodemographics characteristics in males

\begin{tabular}{|c|c|c|c|}
\hline \multirow{2}{*}{ Variables } & \multirow{2}{*}{ n (\%) } & \multicolumn{2}{|c|}{ RR (95\% Cl) } \\
\hline & & Crude & Adjusted \\
\hline $\begin{array}{l}\text { Age } \\
\begin{aligned}<25 \\
25-34 \\
35-44 \\
45-54 \\
\\
55-64 \\
65+\end{aligned}\end{array}$ & $\begin{array}{l}2(4.3 \%) \\
8(8.9 \%) \\
20(21.3 \%) \\
55(44.0 \%) \\
48(60.0 \%) \\
38(59.4 \%)\end{array}$ & $\begin{array}{l}1.00 \\
2.20(0.44-10.82) \\
6.08(1.35-27.35) \\
17.68(4.09-76.38) \\
33.75(7.61-149.61) \\
32.89(7.30-148.18)\end{array}$ & $\begin{array}{l}1.00 \\
2.74(0.53-14.15) \\
6.32(1.35-29.60) \\
16.34(3.62-73.69) \\
18.58(3.96-87.24) \\
12.63(2.57-61.99)\end{array}$ \\
\hline $\begin{array}{l}\text { Educational level } \\
\text { Primary/Secondary } \\
\text { High School } \\
\text { University }\end{array}$ & $\begin{array}{l}66(56.9 \%) \\
96(31.0 \%) \\
9(12.2 \%)\end{array}$ & $\begin{array}{l}9.53(4.33-21.01) \\
3.24(1.55-6.79) \\
1.00\end{array}$ & $\begin{array}{l}5.29(2.09-13.36) \\
3.54(1.51-8.30) \\
1.00\end{array}$ \\
\hline $\begin{array}{l}\text { Employment status } \\
\text { Not employed } \\
\text { Employed }\end{array}$ & $\begin{array}{l}117(55.5 \%) \\
54(18.7 \%)\end{array}$ & $\begin{array}{l}5.42(3.62-8.10) \\
1.00\end{array}$ & $\begin{array}{l}3.36(1.97-5.73) \\
1.00\end{array}$ \\
\hline $\begin{array}{l}\text { Place of residence } \\
\text { Small } \\
\text { Medium } \\
\text { Big }\end{array}$ & $\begin{array}{l}54(40.3 \%) \\
57(37.5 \%) \\
60(28.0 \%)\end{array}$ & $\begin{array}{l}1.73(1.10-2.74) \\
1.54(0.99-2.40) \\
1.00\end{array}$ & $\begin{array}{l}1.55(0.88-2.75) \\
1.20(0.71-2.06) \\
1.00\end{array}$ \\
\hline $\begin{array}{l}\text { Income (PLN per month per capita) } \\
\quad<1000 \\
\quad>=1000\end{array}$ & $\begin{array}{l}152(35.3 \%) \\
19(27.5 \%)\end{array}$ & $\begin{array}{l}1.43(0.81-2.52) \\
1.00\end{array}$ & $\begin{array}{l}0.96(0.46-2.00) \\
1.00\end{array}$ \\
\hline $\begin{array}{l}\text { Leisure-time physical activity } \\
\text { Satisfactory level } \\
\text { Insufficient level } \\
\text { Lack }\end{array}$ & $\begin{array}{l}53(31.6 \%) \\
30(25.2 \%) \\
88(41.3 \%)\end{array}$ & $\begin{array}{l}1.00 \\
0.73(0.43-1.24) \\
1.53(1.00-2.34)\end{array}$ & $\begin{array}{l}1.00 \\
1.04(0.56-1.95) \\
2.21(1.32-3.69)\end{array}$ \\
\hline $\begin{array}{l}\text { Smoking status } \\
\text { Current smoker } \\
\text { Former smoker } \\
\text { Non-smoker }\end{array}$ & $\begin{array}{l}72(35.6 \%) \\
62(44.6 \%) \\
37(23.3 \%)\end{array}$ & $\begin{array}{l}1.82(1.14-2.92) \\
2.65(1.61-4.37) \\
1.00\end{array}$ & $\begin{array}{l}1.50(0.85-2.67) \\
1.76(0.96-3.21) \\
1.00\end{array}$ \\
\hline
\end{tabular}

ple more frequently reported their health as poor or very poor compared to those younger than 25 years. Four percent of men and $10 \%$ of women younger than 25 years of age described their health as poor or very poor whereas in age category $45-54$ years that proportion increased to more than $40 \%$ (men $\mathrm{RR}=16.3$; $95 \%$ CI 3.6-73.7, women RR=7.5; 95\% CI 2.9-19.3), in 55-64 olds to $60 \%$ (men RR=18.6; 95\% CI 4.0-87.2, women RR=10.0; 95\% CI 3.6-27.6) and for people older than 64 years of age to $60 \%$ for men (RR=12.6; 95\% CI 2.6-62.0) and 72\% for women (RR=13.4; 95\% CI 4.6-38.7). The age 45+ years seems to be decisive for describing the health more often as poor or very poor. People with lower educational degree perceived their health as worse compared to those with university diploma (primary/secondary school - men RR=5.3; 95\% CI 2.1-13.4; women 4.6; 95\% CI 2.1-10.1). More than half of unemployed people indicated their health as poor/very poor whereas the percentage of people with that health status among employed was lower (19\%). After adjustment the risk of indicating the health as poor or very poor was 3.4 times higher for unemployed men compared to employed once (95\% CI 2.0-5.7) and 1.5 times higher for unemployed women compared to employed once (95\% CI 0.9-2.1). The place of residence and income level did not significantly influence the self appraisal of health. Men indicating no leisure-time physical activity significantly more frequently described their health as poor and very poor $(\mathrm{RR}=2.2$; 95\% CI 1.3-3.7). That statistically significant association was not observed for women. Current (36\%) and former (45\%) male smokers more frequently described their health as worse compared to non-smokers (23\%) (current smokers RR=1.5; 95\% CI 0.9-2.7; former smokers RR=1.8; 95\% CI 1.0-3.2). The association was not observed in women.

\section{DISCUSSION}

In presented study more the $30 \%$ of study subjects described their health as poor or very poor (36\% of women and $34 \%$ of men). The interesting analysis of self-assessed health in 10 European countries was conducted by Kunst et al. (17). In that analysis data were obtained from national representative interview surveys hold in Finland, Sweden, Norway, Denmark, England, the Netherlands, West Germany, Austria, Italy and Spain. The prevalence of fair/poor health ranged for women from $19.2 \%$ to $54.5 \%$ and for men from $16.7 \%$ to $53.9 \%$. The highest rates were observed for West Germany and the lowest one for Norway. Except Finland all other countries reported higher percentage of fair/poor health for women compared to men, which is comparable to our 
Table 3. Relative risk (RR) and 95\% confidence interval $(95 \% \mathrm{Cl})$ for poor and very poor subjective heath depending on sociodemographics characteristics in females

\begin{tabular}{|c|c|c|c|}
\hline & \multirow{2}{*}{ n (\%) } & \multicolumn{2}{|c|}{ RR (95\% Cl) } \\
\hline & & Crude & Adjusted \\
\hline $\begin{array}{l}\text { Age } \\
\begin{aligned}<25 \\
25-34 \\
35-44 \\
45-54 \\
\\
55-64 \\
65+\end{aligned}\end{array}$ & $\begin{array}{l}6(9.7 \%) \\
13(11.6 \%) \\
13(14.1 \%) \\
59(47.6 \%) \\
50(59.5 \%) \\
59(72.0 \%)\end{array}$ & $\begin{array}{l}1.00 \\
1.23(0.44-3.41) \\
1.54(0.55-4.29) \\
8.47(3.40-21.14) \\
13.73(5.31-35.48) \\
23.94(9.06-63.28)\end{array}$ & $\begin{array}{l}1.00 \\
1.54(0.54-4.37) \\
1.72(0.60-4.92) \\
7.51(2.93-19.26) \\
10.01(3.63-27.57) \\
13.37(4.62-38.69)\end{array}$ \\
\hline $\begin{array}{l}\text { Educational level } \\
\text { Primary/Secondary } \\
\text { High School } \\
\text { University }\end{array}$ & $\begin{array}{l}98(65.3 \%) \\
89(29.7 \%) \\
13(12.3 \%)\end{array}$ & $\begin{array}{l}13.48(6.88-26.41) \\
3.02(1.60-5.68) \\
1.00\end{array}$ & $\begin{array}{l}4.57(2.06-10.14) \\
2.53(1.25-5.22) \\
1.00\end{array}$ \\
\hline $\begin{array}{l}\text { Employment status } \\
\text { Not employed } \\
\text { Employed }\end{array}$ & $\begin{array}{l}149(53.0 \%) \\
51(18.6 \%)\end{array}$ & $\begin{array}{l}4.96(3.37-7.28) \\
1.00\end{array}$ & $\begin{array}{l}1.46(0.87-2.46) \\
1.00\end{array}$ \\
\hline $\begin{array}{l}\text { Place of residence } \\
\text { Small } \\
\text { Medium } \\
\text { Big }\end{array}$ & $\begin{array}{l}58(36.0 \%) \\
61(37.7 \%) \\
81(34.8 \%)\end{array}$ & $\begin{array}{l}1.06(0.69-1.61) \\
1.13(0.75-1.72) \\
1.00\end{array}$ & $\begin{array}{l}1.20(0.71-2.03) \\
1.24(0.74-2.10) \\
1.00\end{array}$ \\
\hline $\begin{array}{l}\text { Income (PLN per month per capita) } \\
\quad<1,000 \\
\quad \geq 1,000\end{array}$ & $\begin{array}{l}188(36.4 \%) \\
12(30.0 \%)\end{array}$ & $\begin{array}{l}1.34(0.66-2.70) \\
1.00\end{array}$ & $\begin{array}{l}1.13(0.47-2.72) \\
1.00\end{array}$ \\
\hline $\begin{array}{l}\text { Leisure-time physical activity } \\
\text { Satisfactory level } \\
\text { Insufficient level } \\
\text { Lack }\end{array}$ & $\begin{array}{l}67(40.1 \%) \\
28(24.6 \%) \\
105(38.2 \%)\end{array}$ & $\begin{array}{l}1.00 \\
0.49(0.29-0.82) \\
0.92(0.62-1.37)\end{array}$ & $\begin{array}{l}1.00 \\
0.92(0.49-1.74) \\
1.27(0.79-2.07)\end{array}$ \\
\hline $\begin{array}{l}\text { Smoking status } \\
\text { Current smoker } \\
\text { Former smoker } \\
\text { Non-smoker }\end{array}$ & $\begin{array}{l}31(29.3 \%) \\
35(35.7 \%) \\
134(38.1 \%)\end{array}$ & $\begin{array}{l}0.67(0.42-1.08) \\
0.90(0.57-1.44) \\
1.00\end{array}$ & $\begin{array}{l}0.94(0.53-1.67) \\
0.97(0.55-1.70) \\
1.00\end{array}$ \\
\hline
\end{tabular}

results. Proportion of people with worse self-esteem comparable to observed in our study was reported in Italy

The study which presents the self perception of health conducted on Polish population was published by Wróblewska (18). In that study $7 \%$ of women and $10 \%$ of men assessed their health status as very good and $4 \%$ and $3 \%$ respectively described their health as very poor. As our results, also this study indicated that women compared to men perceived their health status to be worse but the percentage of people who indicated their health as very poor is about two times higher compared to the cited study ( $8.5 \%$ vs. $4 \%$ for women and $5.8 \%$ vs. $3 \%$ ). Those differences can be explained by the different population subjected to analysis (Łódź vs. Polish population). As it was indicated in the introductory part, Łódź population seems to have worse health status compared to other district in Poland $(14,15)$.

The most significant demographic factors that influence self assessed health, are age and level of education. Older people may perceive their health as worse than young ones due to presence of chronic diseases and physical conditions which are more often present in older age. In the above cited study conducted by Wróblewska more than $80 \%$ of women and $83 \%$ of men aged $15-29$ assessed their health status as good or very good whereas only $8 \%$ of women and $15 \%$ of men aged $60-74$ indicated that category (18). Although the age categories chosen for analysis are little different than in our study the overall association is the same. People with lower level of education may represent the group with higher prevalence of risk factors for chronic diseases such us smoking, alcohol drinking, lack of physical activity and others which can be responsible for worse health perception. Those findings are consistent with other authors $(17,19,20)$.

Although other findings indicate that self-health assessment decreased with decreased level of income we did not confirm that association $(17,21)$. The subjective health seems to be related more to level of education and employment than to income. The level of income is not as so frequently used indicator for determining education or employment status. Although it can provide the information on the access to goods and services, including quality of education and health care but it is not as stable as that other two indicators (22). It can be also due to the fact that the information about the income level obtained by questionnaire data can be biased (about $90 \%$ of responders indicated the level of income per month per capita below 1,000 PLN) although Statistical 
Year Book indicated that average monthly per capita income of households for Łódź district in 2006 was 840 PLN which proved the results that we got in our study (23).

Men indicating no leisure-time physical activity significantly more frequently described their health as poor and very poor than men with satisfactory level of recreational physical activity. The same pattern was observed for women but it was not statistically significant. In other study conducted in Łódź population sufficient level of leisure-time physical activity also affects in the beneficial way self-perception of health (24). In other study Polish women associated "very good" subjective health with presence of recreational physical activity (25). It is also worth noticing that other study have indicated the strong association between insufficient physical activity and lower self-perceived health status as well as worse quality of life parameters, regardless of the actual health status of the subjects with the genetic risk factors (26). The worse self health assessment among current and ex-smokers man compared to non-smokers can be related to older age and lower level of education and the likely higher presence of chronic diseases which could be a reason for worse subjective health perception.

The listed determinants of health like smoking status and physical activity were found as the important priority goals in Polish National Health Program 2007-2015 (14) indicating that all efforts should be undertaken to eliminate cigarette smoking and environmental tobacco smoke exposure and to increase physical activity of recreational nature. The National Health Program is also concentrating on older people to guarantee them healthy environment and opportunity to have healthy and active life.

\section{CONCLUSIONS}

Preventive programs and interventions aimed at improving self-perceived health should concentrate on the increasing of recreational physical activity and elimination of smoking. Those actions should be particularly addressed to people in older category of age.

\section{REFERENCES}

1. Lalonde M. A new perspective on the health of Canadians: a working document. Ottawa: Government of Canada; 1974.

2. Ezzati M, Lopez AD, Rodgers A, Murray CJL. Comparative quantification of health risks: global and regional burden of diseases attributable to selected major risk factors. Geneva: WHO; 2004.

3. Constitution of the World Health Organization. In Handbook of basic documents. 5th ed. Geneva: World Health Organization;1952. p. 3-20.

4. Siegrist J. Impaired quality of life as risk factor in cardiovascular disease. J Chronic Dis. 1987;40(6):571-8.

5. Svärdsudd K, Tibblin G. Is quality of life affecting survival? The study of men born in 1913. Scand J Prim Health Care Suppl. 1990;1:55-60.
6. Miilunpalo S, Vuori I, Oja P, Pasanen M, Urponen H. Self-rated health status as a health measure: the predictive value of self-reported health status on the use of physician services and on mortality in the workingage population. J Clin Epidemiol. 1997 May;50(5):517-28.

7. Idler EL, Angel RJ. Self-rated health and mortality in the NHANES-I epidemiologic follow-up study. Am J Public Health. 1990 Apr;80(4):446-52.

8. Idler EL, Kasl SV, Lemke JH. Self-evaluated health and mortality among the elderly in New Haven, Connecticut, and Iowa and Washington counties, Iowa, 1982-1986. Am J Epidemiol. 1990 Jan;131(1):91-103.

9. Ferraro KF, Farmer MM. Utility of health data from social surveys: is there a gold standard for measuring morbidity? Am Sociol Rev. 1999;64:303-15.

10. Pohjonen T, Ranta R. Effects of worksite physical exercise intervention on physical fitness, perceived health status, and work ability among home care workers: five-year follow-up. Prev Med. 2001 Jun;32(6):465-75.

11. Piko B. Health-related predictors of self-perceived health in a student population: the importance of physical activity. J Community Health. 2000 Apr;25(2):125-37.

12. Thorlindsson T, Vilhjalmsson R, Valgeirsson G. Sport participation and perceived health status: a study of adolescents. Soc Sci Med. 1990;31(5):551-6.

13. Carlson P. Risk behaviours and self rated health in Russia 1998. J Epidemiol Community Health. 2001 Nov;55(11):806-17.

14. Ministry of Health of the Republic of Poland [homepage on the Internet]. Polish National health program for 2007-2015 [cited 2008 Oct 23]. Available from: http://www.mz.gov.pl/wwwmz/index?mr=\&ms=\&ml= pl\&mi $=437 \& m x=0 \& m a=243$. (In Polish.)

15. Demographic Yearbook of Poland 2007. Warsaw: Central Statistical Office; 2007

16. Rywik S, Kupsc W, Piotrowski W, Broda G, Piwonski J, Kurjata P, et al. Polish National Health Survey - Project WOBASZ. Methodological assumptions and logistics. Pol Popul Rev. 2005;27:37-50. (In Polish.)

17. Kunst AE, Bos V, Lahelma E, Bartley M, Lissau I, Regidor E, et al. Trends in socioeconomic inequalities in self-assessed health in 10 European countries. Int J Epidemiol. 2005 Apr;34(2):295-305.

18. Wróblewska W. The male-female differences in health: the role of the health-related behaviours. In: Szamotulska K, editor. Polish population review. Warsaw: GUS; 2005. p. 27.

19. Vingilis ER, Wade TJ, Seeley JS. Predictors of adolescent self-rated health. Analysis of the National Population Health Survey. Can J Public Health. 2002 May-Jun;93(3):193-7.

20. Šplíchalová A, Tomášková H, Šlachtová H. Risks of different self-approach to health in an industrial city population. Cent Eur J Public Health. 2003 Sep;11(3):142-8.

21. Erginoz E, Alikasifoglu M, Ercan O, Uysal O, Ercan G, Albayrak Kaymak $\mathrm{D}$, et al. Perceived health status in a Turkish adolescent sample: risk and protective factors. Eur J Pediatr. 2004 Aug;163(8):485-94.

22. Kozakiewicz K, Tendera M, Piwoński J, Głuszek J, Wiercińska E, Bielecki W, et al. Socioeconomic factors and their differentiation in the Polish population. In: Szamotulska K, editor. Polish population review. Warsaw: GUS; 2005.

23. Statistical Yearbook of the Republic of Poland 2007: Łódź District. Warsaw: Central Statistical Office; 2007.

24. Kaleta D, Makowiec-Dąbrowska T, Jegier A. Leisure-time physical activity, cardiorespiratory fitness and work ability: a study in randomly selected residents of Łódź. Int J Occup Med Environ Health. 2004;17(4):45764.

25. Nowak M. Factors determining physical fitness self-evaluation and health self-evaluation in physically active women. New Med. 2006;9(1):1925.

26. Kwaśniewska M, Bielecki W, Drygas W. Sociodemographic and clinical determinants of quality of life in urban population of Poland. Cent Eur J Public Health. 2004 Jun;12(2):63-8. 